\title{
Strategy, technology and organisational alignment: Key components of CRM success
}

Received (in revised form): 18th April, 2005

\section{Mary Lou Roberts}

is a member of the Marketing faculty at the University of Massachusetts, Boston where she teaches a variety of marketing communications courses. Her PhD in marketing is from the University of Michigan. Dr Roberts is the author of 'Internet marketing: Integrating online and offline strategies' (2nd edition forthcoming, Atomic Dog Publishing). She is the senior author of 'Direct marketing management', 2nd edition. (Prentice-Hall, 1999).

\section{Raymond R. Liu}

is a member of the Marketing faculty at the University of Massachusetts, where he teaches courses in marketing research and data mining. He holds a PhD in marketing from the University of Oregon. His research has been published in numerous journals in the USA and Europe. He frequently presents at professional conferences in the USA and his native country of China. He is the senior author of 'Customer relationship management' (forthcoming, McGraw-Hill).

\section{Karyl Hazard}

is a marketing analyst at L. L. Bean in Freeport, Maine. Before that she was an associate consultant with Bain \& Company in Boston, MA. She holds an MBA degree from the University of Massachusetts and a bachelor's degree from Boston College.

Mary Lou Roberts P.O. Box 31,

N. Eastham, MA 02651, USA.

Tel: +1 617287 7733;

Fax: +1508240 6127; e-mail:

robertsm@loincast.net

\begin{abstract}
The role of technology in successful customer relationship management (CRM) implementation is a perennial subject of concern to marketers. This paper reviews CRM studies, especially those with empirical data about the role of technology. The studies consistently indicate that technology is a necessary but not sufficient factor in the ultimate success of a CRM system. The paper then presents a model of CRM implementation that positions technology as an enabler of CRM success, but identifies other marketing and organisational issues as key drivers. It includes a case history of successful CRM implementation that features a staged approach to both technology integration and organisational readiness.
\end{abstract}

\section{INTRODUCTION}

Customer relationship management (CRM) gained prominence as a marketing sub-discipline in the 1990s, fueled by publications like 'The one to one future'" and 'The loyalty effect'. ${ }^{2}$ Reichheld's work was especially powerful in highlighting the gap between the cost of acquiring customers and the cost of retaining them. The quest for competitive advantage and profitability triggered a rush to implement CRM programmes in enterprises both large and small in all corners of the globe.
Over a decade later, the question of whether these enterprises are achieving a return on their CRM investment is still a hotly debated issue. Consultants at McKinsey and Company report that, 'According to several recent surveys, two-thirds of the companies that have invested in CRM technology solutions consider them disappointments. ${ }^{3}$ In 2004 , a global study of executives conducted by IBM reported, ' 85 per cent of companies in America, Europe and Asia - large and small, across every industry — are not feeling fully successful with CRM. ${ }^{4}$ 
This seems to represent marketing conventional wisdom, but an industry-specific study by the McKinsey consultants provides another perspective. They probed more deeply into the CRM situation in the insurance industry and found that, 'Many insurance companies have experienced modest success or better with their CRM investments. ${ }^{5}$ A benchmarking study identified 200 organisations that met implementation criteria in various industries in both Europe and the USA. None of the 55 firms that responded to the questionnaire considered their CRM initiative fully implemented, but the author concludes: 'CRM continues to be of strategic importance and is being leveraged by technological potentials. ${ }^{6}$

This last citation highlights one of the important controversies in CRM today - the role of technology in CRM success or failure.

\section{TECHNOLOGY AND CRM}

The role of technology in CRM success or failure has been widely debated.

There is no question that CRM must be data driven in all but the smallest organisations where face-to-face customer contact prevails. Data-driven CRM requires robust databases and analytic systems plus the ability to deliver information to users as required. Even though this premise seems indisputable, it begs the question about the criticality of technological solutions in CRM success or failures.

Anecdotal evidence can be presented on both sides. Consultants can cite situations in which the technology clearly failed, leading to the failure of the entire initiative. In other situations, indicators equally clearly point to organisational shortcomings as reasons for the failure of CRM implementation. Only in recent years have rigorous studies begun to provide empirical evidence about drivers of success or failure.

In 2002, Day and Van den Bulte studied the impact of CRM on the attainment of competitive advantage and business unit sales growth and profitability. $^{7}$ Their study concentrated on US businesses with over 500 employees, reasoning that smaller companies have an easier task in deploying CRM. The central construct for the study was 'customer relating capability,' which has three components - orientation, information and the configuration. Results from 345 senior managers indicated that the configuration component, which consists of organisational structure, incentives and accountability, was the most important element in achieving strong performance, positional advantage and customer-relating expertise. Also important was the orientation component, which described the organisational culture as it related to developing and sustaining customer relationships. The third component, information, which includes both customer data and information technology, 'contributes little to the overall capability once a minimum level of competency has been attained'.

A study by Reinartz et al. in 2004, found that there was no empirical evidence from a strategy perspective about either the characteristics of successful CRM implementations or the reasons that they fail. ${ }^{8}$ They conceptualise the CRM process as having three phases - relationship initiation, relationship maintenance and relationship termination. In their models the impact of process on economic performance is moderated by organisational alignment and technology. They obtained data from 211 senior managers in consumer products companies in Austria, Germany and 
Table 1: Strategic drivers of CRM success

\begin{tabular}{ll}
\hline Driver & Reference numbers \\
\hline Strategy and planning & \\
Planning input from all business units & $9,10,11$ \\
Presence of strategic goals & 12 \\
Achieving operating efficiency & 13 \\
Organisational alignment & 14 \\
Organisational structures and incentives & 15 \\
& \\
Implementation - organisational aspects & 16,17 \\
Train end users & $18,19,20$ \\
Modular implementation & $21,22,23$ \\
Organisational change management & 24 \\
Central coordination of project & 25 \\
Top management support & 26 \\
Organisational culture & 27 \\
High degree of CRM process implementation & \\
Implementation - technological aspects & 28 \\
Centralised CRM systems & 29 \\
Centralised customer database & 30 \\
Sophistication of CRM technology (negative impact) & \\
Evaluation & 31 \\
Organisational controls & \\
\hline
\end{tabular}

Switzerland and found that CRM processes did appear to have a positive impact on objectively measured performance, especially in the initiation and maintenance stages of customer relationships. Organisational alignment had a small impact in the initiation stage, but not in maintenance and termination. CRM technology did not have a significant impact on objective performance in any of the three stages.

The evidence so far reported suggests that strategic, organisational and technological issues are all important in achieving CRM success. Table 1 organises the data from empirical studies in a simple process format. This helps to align the currently-available evidence about strategy, technology and organisational alignment, but it does not provide a process that synthesises what is known into a CRM-specific process that can guide both practice and research.

Organising the empirical evidence in this manner also suggests that the empirical research to date has paid little attention to issues associated with the evaluation of CRM programmes.

Measuring the impact of CRM systems on customers and on the performance of the enterprise is critical to their ongoing success.

\section{STEPS TO SUCCESSFUL CRM IMPLEMENTATION}

The number of publications that recommend a series of steps that increase the probability of successful CRM implementation seems infinite. There are two problems with the large amount of literature surveyed for this paper:

- CRM success is usually not rigorously defined. The implication in recent years is that 'success' is synonymous with a positive return on investment on the CRM installation.

- The steps are usually based on experience and anecdotal evidence, not rigorous research.

With these two issues in mind, the authors scanned the literature for a series 


\section{CRM Process Model}

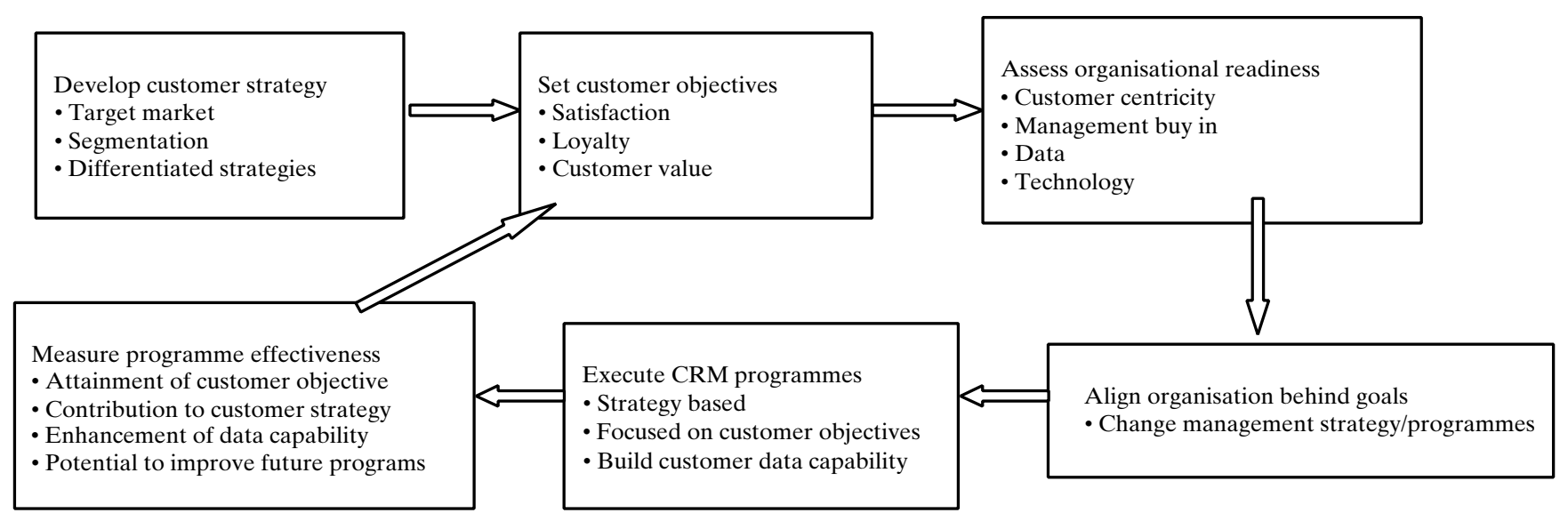

Figure 1: CRM process model

of steps that is consistent with the empirical evidence they have reported and that represents the preponderance of opinion among CRM users, solutions providers and integration consultants. The synthesised process is shown in Figure 1. Our version focuses on the corporate and marketing requirements for a successful process. It does not provide detail on the important technical issues of selecting and implementing a CRM software solution. It does, however, position that activity within the overall process.

\section{Developing a customer strategy}

The basic tenet of CRM is that it is cheaper to retain an existing customer than to acquire a new one. Not all customers are equally profitable and thus equally desirable, however. The essence of a customer strategy is to identify profitable customers. Simple recency, frequency, montetary value (RFM) analysis is often used to identify best customers. The most desirable approach is to identify those customers who have a high customer lifetime value (CLV) and to develop differentiated strategies for dealing with different CLV segments.
Within the target market defined by marketing management, there are invariably segments that differ in terms of customer profitability. Many writers have pointed out that, in the absence of active customer management, the Pareto rule - 20 per cent or fewer of the customers produce 80 per cent or more of the profit - always holds. Many of the customers, in fact, are actually unprofitable.

The CRM challenge is to identify profitable customers and develop strategies to retain them and make them more profitable. The same strategic segmentation process should identify segments of unprofitable customers and find ways to either make them profitable (increased sales or lower costs of service, for example) or to terminate them.

Bell et al. describe the traditional approach to CLV as 'Forecasting of the stream of profits attributable to the customer and the computing of a discounted present value'. ${ }^{32}$ They also point out that there is a growing stream of literature concerned with the computation of CLV. Rust et al. ${ }^{33}$ have recently shown that the calculation of CLV can be enhanced by the addition of competitive actions and brand-switching 


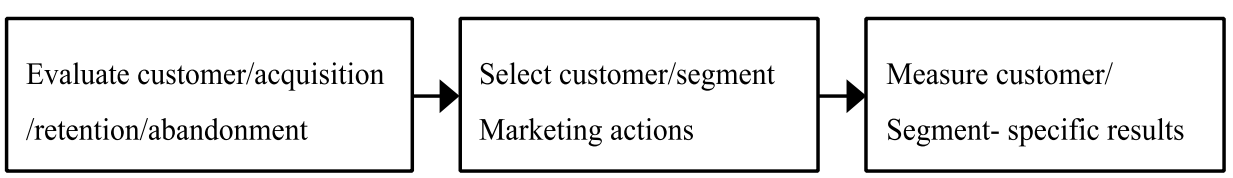

Figure 2: Bell and colleagues' segmentation process. ${ }^{35}$

behaviour to the commonly used model of individual customer profitability.

Bell and colleagues' ${ }^{34}$ segmentation process is described in Figure 2. This segmentation process highlights the important role of technology at this stage of CRM. The ability to develop strategic segments depends on the existence of a robust customer database and segmentation models that effectively capture the intricacies of customer behaviour over time. The technology, however, only provides input to the decisions about what marketing actions will be taken to implement differentiated strategies for profitable and unprofitable segments. Those decisions — which might include actions such as enhanced loyalty programmes for profitable customer segments or implementation of user fees for unprofitable customer segments - are the key to strategic success. The effectiveness of the actions will only be clear if careful tracking and measurement can isolate the impact of specific marketing actions on individual customer segments. The differentiated strategies, coupled with the ability to track and measure at the segment level, will determine specific customer objectives.

\section{Setting customer objectives}

From a conceptual perspective, it seems inarguable that the ultimate objective is defined by CLV, since only CLV incorporates, over time, both the revenues derived from and the costs associated with serving specific customers and customer segments.

Peppers and Rogers ${ }^{36}$ offer a more detailed perspective on the importance of a strategy that is informed by CLV analysis. They distinguish between 'actual value', the customer's current value to the company, and 'potential value', the ability to grow the value of the customer over time. Customers with the highest actual value are key retention targets. Customers with high potential value represent important growth targets. Customers with a combination of low actual and potential value are targets for cost reduction. Because the 80:20 rule - by which 20 per cent of customers produce 80 per cent of profits regardless of the profile of the customer base invariably holds true, this kind of analysis is essential to profitability.

If the concept of CLV seems inarguable, however, the reality is not easily attainable for many enterprises. If they do not currently have a customer database with the necessary data for CLV modelling, experts estimate that it takes at least two years to build one. If the purchase cycle is lengthy, it can take even longer.

In the meantime, businesses will have to work with desirable, but far from optimal, customer objectives; customer satisfaction and retention levels are two that are often used. Use of objectives such as these ignore the issue of differential customer profitability and are unlikely to lead to satisfactory, much less optimum, results.

\section{Access organisational readiness}

Implementing a CRM process is a complex undertaking, requiring buy-in and effort across the organisation. 
Agarwal et al. ${ }^{37}$ put the issue into perspective:

Building, modifying, or running a CRM solution involves a large cast of characters. It can include systems experts; business analysts; backroom operations specialists; managers who use customized reports to fine-tune sales, marketing, and customer service strategies; and frontline sales and service people, who are responsible for inputting much of the data the CRM initiative needs to yield rich insights and for acting on them.

The cast of characters also includes managers at all levels. When asked about the single most important reason for CRM success, marketing executives replied that strategy (32 per cent) and executive commitment ( 26 per cent) were most important by a considerable margin. ${ }^{38}$ Kale adds that, 'Without support and commitment from top management, even the most brilliant CRM undertaking is doomed to failure'. ${ }^{39}$ A CRM process invariably requires changes throughout the organisation and this will not occur without enduring top management commitment.

The entire organisation may need to be realigned to focus on the customer. The majority of enterprises are organised around products, not customer needs. People work, and information travels in vertical silos - not horizontally across the organisation to all customer touchpoints. Performance metrics may actually foster an environment that promotes isolation of people and activities, not integration.

The list of specific issues that need to be in place prior to the implementation of a CRM system is lengthy. These are the major issues, in no particular order of priority:

- Job descriptions, performance measures and compensation systems

- Training programmes

- Both front- and back-end processes that are organised around the customer life cycle

- Processes that extend beyond the corporate boundary to both suppliers and customers

- Differentiated customer strategies

- An integrated database with required customer and supplier information, designed to meet both programming and analytic needs

- People, data, and technology that are all focused on seamless excellence in the customer experience

- Proactive customer service

- Corporate performance goals and metrics that are aligned with customer strategies

- Buy-in at all levels of the organisation, including top management

- Realistic expectations of performance improvement and time requirements. ${ }^{40-43}$

A satisfactory readiness state for some of these issues will require business process reengineering. The process reengineering may involve suppliers and customer-facing channel members as well as members of the organisation. Other issues will require organisational restructuring, personnel adjustments and training at all levels. Some issues may require both process reengineering and changes in organisational culture and workflows. None of them will reach a satisfactory readiness state overnight. Top management is responsible for creating the disciplined and focused environment in which the momentum for change can be maintained, often over a considerable period of time. For a detailed assessment of these issues see Kotter. ${ }^{44}$

\section{Align the enterprise behind corporate CRM goals}

As the previous section makes clear, most organisations will need to reorganise and 
reorient many aspects of their operations in order to make them customer centric and seamlessly effective from end to end. Some of the changes will be in the fundamental processes of the enterprise, requiring time and expense for process reengineering, but are essentially operational in nature. Others will require a fundamental transformation in organisational culture - a shift from a functional, product-oriented mindset to one that is customer centric and not bound by functional and product constraints. This calls for an enterprise-wide programme of change management.

There is a sizeable literature on change management that is beyond the scope of this paper. There is, however, a series of actions recommended by Prof John Kotter that is actionable and that captures much of the extant knowledge. ${ }^{45}$ In order for organisational transformation to take place, it must be viewed as an ongoing process requiring continuing commitment and leadership from top management. His stages of transformation are:

- Establish a sense of urgency. In the case of UnumProvident, the merger of two large insurance providers, both of which were the result of recent mergers, lead to the realization that successful integration was necessary to ward off chaos. Four years of organisational and systems change took place before a CRM system was put in place.

- Form a powerful guiding coalition. At UnumProvident an Office of Program Management was created to oversee the CRM project.

- Create a vision. The vision at UnumProvident was an organisation that provided seamless service to customers across product lines and geographical entities.
- Communicate the vision. Training of sales and customer service personnel was an early step in the process.

- Empower others to act on the vision. Reorganisation and training were both necessary to break down product silos. In addition, a leader who was comfortable executing an information-driven strategy was needed in the sales area.

- Plan for and create short-term wins. The risk management approach at UnumProvident was adopted in order to make changes and extract value from them on an incremental basis.

- Consolidate improvements and produce more change. UnumProvident recognises that its CRM strategy is still in an early stage and expects more progress, using the same careful planning and staged execution.

- Institutionalise new approaches.

Neither the importance nor the challenge of transforming an organisation from product centric to customer centric should be underestimated. As in the UnumProvident case, the transformation is likely to take years. Without organisational transformation, however, the CRM system will not be successful.

\section{Execute CRM programmes}

Kotter's transformation stages reinforce what many managers have learned from experience - that it is important to identify programmatic CRM activities that can produce early and noticeable returns. Whether it be for a high value customer retention programme, moderate-value customer upgrade, lapsed customer reactivation or one of many other possibilities, activities should be well designed, meticulously executed and appropriately measured to demonstrate the potential of the CRM initiative.

Individual programmes should focus 
Table 2: Examples of required metrics

\begin{tabular}{|c|c|c|c|c|c|}
\hline \multicolumn{6}{|c|}{ Customer Strategic Marketing Sales Promotion Customer Service } \\
\hline $\begin{array}{l}\text { Customer } \\
\text { satisfaction }\end{array}$ & $\begin{array}{l}\text { Increase in } \\
\text { number of high } \\
\text { value customers }\end{array}$ & $\begin{array}{l}\text { Lead } \\
\text { conversion rate }\end{array}$ & $\begin{array}{l}\text { Average length } \\
\text { of sales cycle }\end{array}$ & $\begin{array}{l}\text { Number of } \\
\text { qualified leads }\end{array}$ & $\begin{array}{l}\text { First call } \\
\text { resolution rate }\end{array}$ \\
\hline $\begin{array}{l}\text { Share of } \\
\text { wallet }\end{array}$ & Increase in CLV & $\begin{array}{l}\text { Return on } \\
\text { marketing } \\
\text { expenditure }\end{array}$ & $\begin{array}{l}\text { Revenue per } \\
\text { salesperson }\end{array}$ & $\begin{array}{l}\text { Return on } \\
\text { promotional } \\
\text { expenditure }\end{array}$ & $\begin{array}{l}\text { Average speed } \\
\text { of reply (e-mail) }\end{array}$ \\
\hline
\end{tabular}

Adapted from Kingstone, $2004^{46}$

on a specific customer value segment, carrying out a differentiated strategy developed for that segment alone. Each will have metrics that are specific to the segment and to specific programmatic objectives. Top marketing management has the responsibility to see that all segments are given attention and resources that are in line with their current value and growth potential.

Each programme should add to the information capability of the CRM system. The data that are needed for analytics and execution and the data that will be returned to the integrated database should be specified as part of the programme planning process.

\section{Measure programme effectiveness}

Metrics need to be carefully identified for each programme and for the CRM initiative as a whole. As noted above, new metrics may have to be developed to reflect the cross-functional requirements of CRM. Figure 1 provides guidelines for identifying metrics: they must measure the attainment of customer objectives, programme-by-programme; they must measure the contribution of the individual programme to the overall CRM initiative; each programme should contribute to the data capability of the enterprise; and there should be knowledge management capabilities in place that lead to learning that will improve future programmes.

Metrics will be somewhat unique to the enterprise and to the programmatic activity, but there are generic examples. The examples shown in Table 2 are stated along functional lines. This may have to be modified for the reorganised, customer-centric enterprise. In addition, not all programmes impact all CRM activities, and that should be taken into account. All programmes should, however, have customer metrics that match customer objectives and should be held accountable for contribution to enterprise customer strategy. With those ideas in mind, Table 2 gives a brief example of marketing activities and typical metrics. The number of possible metrics is limited only by the number of customer and strategic objectives and the number of CRM activities involved in each individual programme.

\section{CONCLUDING OBSERVATIONS ON THE ROLE OF TECHNOLOGY IN CRM}

This paper set out to frame the issue of technology in CRM systems as part of the larger process for successful CRM implementation. The preponderance of evidence suggests that technology is only one of the drivers of CRM success. ${ }^{47}$

Table 3 gives a number of quotations from various experts in the field. Taken together they suggest that technology is an enabler of success, but not one of the most important drivers. Here, it is concluded that, in order to obtain return on the CRM technology investment, 
Table 3: Perspectives on the role of technology in CRM implementation

'Many executives stumble into one or more of four pitfalls while trying to implement CRM. Installing CRM technology before creating a customer-focused organization is perhaps the most dangerous pitfall.'

'Information technology is the conduit that aids in practising and perfecting your marketing practices but, in and of itself, technology does little to further customer retention.'

'Finally, use technology. Easy-to-use and affordable software options abound. Just make sure you're a good "carpenter" before buying the latest "hammer".'

'Information technology is merely a necessary condition.'
Rigby et al. $2002^{48}$

Kale, $2004^{49}$

Thompson $^{50}$

Day and Van den Blute, $2002^{51}$ there are steps that need to be taken before the CRM system is selected and installed.

The CRM process synthesised here requires substantial change on the part of most organisations to create an

environment that is customer centric and ready for the implementation of an integrated CRM system. It necessitates the development of an overall customer strategy with differentiated strategies for identified customer segments. This is followed by the setting of customer objectives focused on maximising customer value. Next comes the assessment of organisational readiness to execute CRM across the organisation. Organisation alignment entails a long-term change management process that creates the organisational milieu in which CRM can flourish. Successful CRM requires the execution of separate programmes to address the requirements of each customer segment. Finally comes the development and rigorous use of metrics specifically designed to measure the effectiveness of each CRM programme and to improve the productivity of every future programme - an area too often given scant attention in the authors' experience.

Each stage of this process offers opportunities for research that drills down into that particular step and provides guidance in design and execution. It has already been noted that the evaluation stage, in particular, seems to have attracted little attention from researchers who are developing and empirically testing models of the overall CRM process or its individual stages.

Careful consideration of this process suggests another conclusion, not unique to this set of authors, that CRM is a long-term process of organisational change and development. If it is undertaken with the expectation of a 'quick fix' for tactical or strategic problems of any kind, it is most likely doomed to failure. By the same logic, if technology is looked upon as the solution to a problem instead of as a way of implementing a strategically sound solution, CRM will fail to provide a return on the technology investment.

Customers have ever-increasing expectations concerning the quality of experience they receive from marketers to whom they give their loyalty. Marketers are faced with a complex, multichannel environment that they must successfully manipulate in order to create experiences that satisfy discerning customers. A smoothly functioning CRM system is essential, but technology alone will not suffice. A long-term process of organisational alignment and continuous improvement is essential in achieving successful CRM deployment 
that produces a satisfactory return on organisational investment.

\section{Acknowledgment}

Personal Interview with Bob Best, Portland, Maine, December 13, 2004.

\section{References}

1 Peppers, D. and Rogers, M. (1993) 'The one to one future', Doubleday, New York, NY.

2 Reichheld, F. F. (1996) 'The loyalty effect', Harvard Business School Press, Boston, MA.

3 Harding, D., Cheifetz, D., DeAngelo, S. and Zeigler, E. (2003) 'Unlock the hidden potential in your CRM investments', McKinsey \& Company, retrieved on November 18, 2004 from http://www.mckinsey.com/ clientservice/marketing/pdf/Solutions_UnlockingCRM_potential.pdf.

4 IBM Business Consulting Services, 'CRM done right', retrieved on January 7, 2005 from http://www-1.ibm.com/services/us/index.wss/ rs/bcs/a1002689.

5 Agarwal, A., Harding, D. P. and Schumacher, J. R. (2004) 'Organizing for CRM', The McKinsey Quarterly, No. 3, pp. 81-91.

6 Alt, R. and Puschmann, T. (2004) 'Successful practices in customer relationship management', 'Proceedings of the 37th Hawaii International Conference on System Sciences', pp. 1-9.

7 Day, G. A. and Van den Blute, C. (2002) 'Superiority in customer relationship management: Consequences for competitive advantage and performance', Working Paper, The Wharton School, University of Pennsylvania, pp. 1-49.

8 Reinartz, W., Krafft, M. and Hoyer, W. D. (2004) 'The customer relationship management process: Its measurement and impact on performance', Journal of Marketing Research, Vol. XLI, pp. 293-305.

9 Alt and Puschmann (2004) op. cit.

10 Harding, et al. (2003) op. cit.

11 Harding, D., Cheifetz, D., DeAngelo, S. and Ziegler, E. (2004) 'CRM's silver lining', Marketing Management, Vol. 13, No. 2, March/April, pp. 27-32.

12 Alt and Puschmann (2004) op. cit.

13 Alt and Puschmann (2004) ibid.

14 Reinartz et al. (2004) op. cit.

15 Day and Van den Blute (2002) op cit.

16 Harding et al. (2004a) op. cit.

17 Harding et al. (2004b) op. cit.

18 Alt and Puschmann (2004) op. cit.

19 Harding et al. (2004a) op. cit.

20 Harding et al. (2004b) op. cit.

21 Alt and Puschmann (2004) op. cit.

22 Harding et al. (2004a) op. cit.

23 Harding et al. (2004b) op. cit.

24 Alt and Puschmann (2004) op. cit.

25 Alt and Puschmann (2004) ibid.

26 Day and Van den Blute (2002) op cit.
27 Renartz et al. (2004) op. cit.

28 Day and Van den Blute (2002) op cit.

29 Day and Van den Blute (2002) ibid.

30 Reinartz et al. (2004) op. cit.

31 Day and Van den Blute (2002) op cit.

32 Bell, D., Deighton, J., Reinartz, W. J., et al. (2002) 'Seven barriers to customer equity management', Journal of Service Research, Vol. 5, No. 1, pp. 77-86.

33 Rust, R. T., Lemon, K. N. and Zeithaml, V. A (2004) 'Return on marketing: Using customer equity to focus marketing strategy', Journal of Marketing, Vol. 68, No. 1, pp. 109-127.

34 Bell et al. (2002) op. cit.

35 Bell et al. (2002) ibid.

36 Peppers and Rogers Group (2003) 'Unlocking the value of your CRM initiative', retrieved on January 7, 2005 from www.1 to1.com.

37 Agarwal et al. (2004) op. cit.

38 Hapoienu, S. (2005) 'What is CRM?', www.reveries.com last accessed 12th February, 2005.

39 Kale, S. H. (2005) 'CRM failure and the seven deadly sins', Marketing Management, September/October, pp. 42-46.

40 Rigby, D. K., Reicheld, F. and Schefter, P. (2002) 'Avoid the four perils of CRM', Harvard Business Review, February, pp. 5-11.

41 Agarwal et al. (2004) op. cit.

42 Kale (2005) op. cit.

43 Kingstone, S. (2005) 'Customer-centric CRM', from www.yankeegroup.com last accessed 26th January, 2005.

44 Kotter, J. P. (2005) 'Lead change successfully', 2nd edition, Harvard Business Review, February, pp. 137.

45 Kotter, J. P. (1995) 'Leading change', Harvard Business Review, March/April, pp. 4-11.

46 Kingstone (2005) op. cit.

47 Thompson, B. 'Successful CRM', www.rightnow.com. last accessed 20th January, 2005.

48 Rigby et al. (2002) op. cit.

49 Kale (2005) op. cit

50 Thompson (2005) op. cit.

51 Day and Van den Blute (2002) op. cit.

52 Anon (1999) 'UNUM Corporation and Provident Companies, Inc. announce date for meetings of shareholders to approve merger', 2nd June, www.unumprovident.com/newsroom/.

53 Anon (2005) UnumProvident 'Corporation reports fourth quarter 2004 results', www.unumprovident.com/newsroom/ last accessed 2nd February.

\section{Appendix}

\section{CRM at UnumProvident}

UnumProvident was formed in 1999 as the result of a merger between Unum 
and Provident. At that time Portland, Maine-based Unum was a leading supplier of disability insurance in North America and the United Kingdom. It also offered other lines including group life insurance, long-term care insurance and payroll-deducted voluntary benefits programmes. Chatanooga,

Tennessee-based Provident also supplied disability insurance and related products throughout the USA and Canada.

The merger created the largest provider of group and individual disability insurance in the USA and the UK. It insures more than 25 million people and employs more than 12,000 people worldwide.

The opportunities for synergies in the product lines of the merged company were great. So were the challenges of consolidating almost 30 different product-based information systems. Integrating these diverse systems into two standard operating platforms required both process and organisational change. The end goal was clear: to efficiently provide customers with multiple product offerings from a single, unified company.

According to Bob Best, Chief Information Officer and Executive Vice President of Customer Service Centers, the newly-merged company approached the challenging task of integrating people, products, processes and technology in a deliberate and staged fashion. While other companies were installing powerful but expensive technology, UnumProvident was engaged in the painstaking process of integrating what had been four separate companies as recently as the early 1990s, into a single global entity.

Bob Best has not only been in the insurance business for thirty years, he has been a member of three out of the four merged companies that are now UnumProvident. He credits that experience with his ability to effectively manage the post-merger change that involved not only information systems but people and diverse cultures within the organisation. One pressing need was training the sales and service teams. They were accustomed to working in product silos. In the new organisation they were required to offer information and support across all UnumProvident's product lines.

Management, however, realised that too much change too quickly could threaten the success of the merger. They adopted a risk management strategy that helped them avoid major pitfalls. It called for an approach in which systems were created and value was extracted from them in an incremental fashion. This proved to be more successful than viewing integration as a large, multi-year project that would not produce value until completion.

After four years of post-merger integration efforts, technology integration was in place and the organisation was focused on the customer. UnumProvident's management team recognised a need for more than just data warehousing technology and a customer focused sales/service team to support their strategy, however. The company needed to put greater focus on business planning and data utilisation. A CRM strategy would propel the company to the next level of integration success.

UnumProvident had already undergone a significant realignment of people and processes due to the merger, but additional enhancements were required to support the CRM strategy. For example, UnumProvident looked externally for a person used to operating in an information environment to head up the sales organisation. The idea was to bring a much more thoughtful and analytical approach to the sales process and reduce the 'fly by the seat of your pants' mentality. 
In addition, an Office of Programme Management was created to facilitate the execution of the CRM strategy. Not only has this office been critical in working to educate and monitor employees on their roles in the effort, but it also created a blueprint of analytics that would be used as a scorecard for CRM strategy. DWL Customer $^{\mathrm{TM}}$ was selected as the data aggregation tool and ONYX as the front-end CRM tool. While both technologies are in place and people have been trained, the initiative is still viewed as being at an early stage.

Today, UnumProvident continues to work to bring integrated solutions to customers and to develop and expand their market leadership. Bob Best acknowledges that the organisational changes driven by the merger were a critical foundation for the CRM strategy that is making this possible. Among the factors that he considers critical to UnumProvident's CRM strategy success to date are:

1 Use of a prototype strategy where several prototypes are established and measured (risk management);

2 Strong linkages between IT and business functions;

3 Solid data and information foundations;

4 Creation of the Office of Program Management to facilitate execution; and

5 A business strategy that requires CRM.

UnumProvident continues to 'think big' in terms of its strategy while using a risk management approach and 'small steps' to achieve successful execution. 